\title{
EVALUATION OF A DYNAMIC METHOD FOR CALIBRATION OF DYE DILUTION CURVES
}

\author{
BY \\ RICHARD EMANUEL AND JOHN NORMAN \\ From the Institute of Cardiology and National Heart Hospital, London
}

Received September 4, 1962

Dilution techniques were first used for the measurement of the cardiac output in man by Hamilton et al. (1928). The original method involved multiple arterial samples and subsequent determination of the dye concentration in each sample.

The introduction of continuously recorded dilution curves (Friedlich, Heimbecker, and Bing, 1950; Nicholson and Wood, 1951; Milnor et al., 1953) overcame the need for multiple samples but introduced the problem of calibrating the time concentration curve obtained. Milnor et al. (1953) drew attention to the inherent errors in the practice of calibrating from a single venous sample obtained some minutes after the dye curve had been obtained, and this led Emanuel, Lacy, and Newman (1957) to develop the technique of integral sampling. This overcame many of the previous problems, but the concentration of dye in the sample for calibration still had to be determined.

Sparling et al. (1960) devised a technique that eliminated the need for a calibration sample, thus avoiding any form of chemical or spectrophotometric analysis. They compared the area of the dilution curve obtained from the patient with that derived from a small calibration system built into the sampling line. In order to determine the accuracy of their method we constructed a model so that the "calculated" flow using their method of dynamic calibration could be compared with the actual flow through the system.

\section{THEORY}

The area of a dilution curve is controlled by two factors, the quantity of dye injected and the flow through the system. If we assume that the areas of the dilution curve from both patient and calibration system are the same, then the flow rate in the patient $(Q)$ is related to the flow rate in the calibration system $(Q c)$ as the quantity of dye injected into the patient (I) is related to the quantity of dye injected into the calibration system (Ic), i.e. $Q: Q c$ as $I: I c$, or $Q=\frac{I \times Q c}{I c}$.

The areas of the dilution curves from the patient (A) and calibration system (Ac) are seldom identical; correction for this difference must therefore be made.

$$
\mathrm{Q}=\frac{\mathrm{I} \times \mathrm{Qc}}{\mathrm{Ic}} \times \frac{\mathrm{Ac}}{\mathrm{A}}, \text { or } \mathrm{Q}=\frac{\mathrm{I} \times \mathrm{Qc} \times \mathrm{Ac}}{\mathrm{Ic} \times \mathrm{A}} \text {. }
$$

This equation can be solved for Q, as I, Ic, A, Ac, and Qc can all be measured.

\section{METHOD}

A diagram of the model used is shown in Fig. 1. A double roller pump (A) was set to deliver an arbitrary flow through the system and a cuvette withdrawal pump (B), capable of maintaining a constant sampling rate, was used to withdraw fluid through the cuvette (C) (Norman, 1959) from the sampling site (D). A known quantity of dye was injected into the calibration loop (E) and the dilution curve obtained (calibration curve) was recorded on a Honywell Brown Recorder. With all aspects of the recording and measuring system unchanged this procedure was followed by the injection of a known quantity of the same dye solution at the injection site (F) and a dilution curve was obtained from the model system.

The flow through the model, including that withdrawn through the cuvette, was collected and measured, 308 


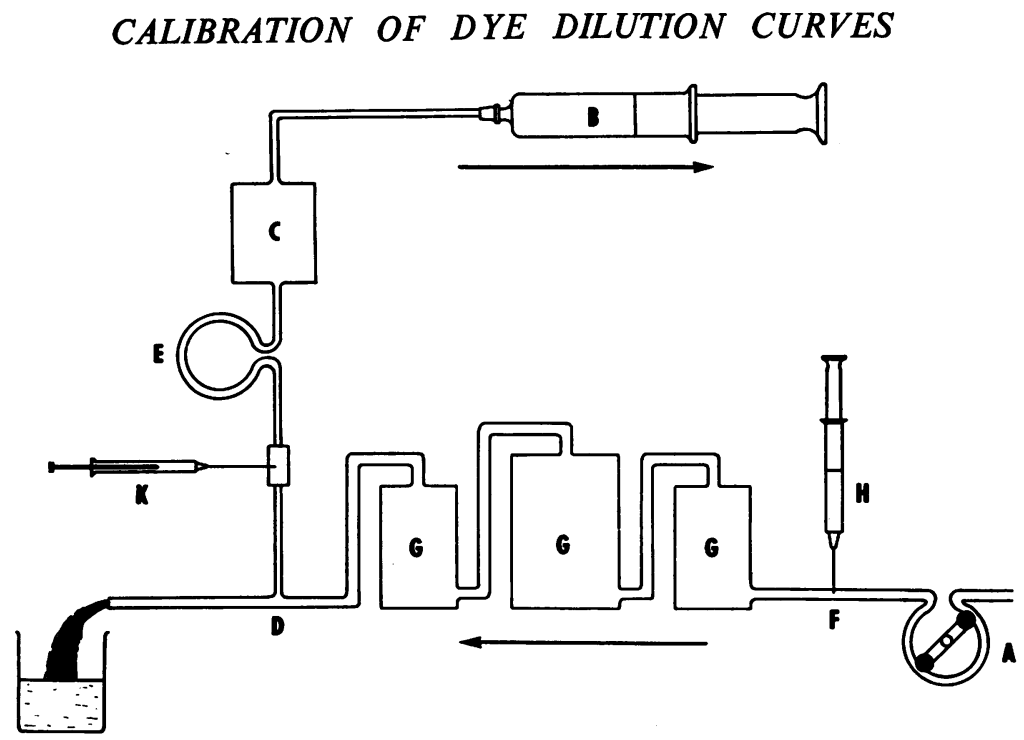

FIG. 1.-Diagram of model system. A, double roller pump; B, cuvette withdrawal pump; C, cuvette; D, sampling site; E, calibration loop; F, injection site; G, aspirators; $\mathrm{H}, 5 \mathrm{ml}$. injection syringe; and $\mathrm{K}$, micro-injection syringe.

and the minute volume calculated (measured flow). The area of the two dilution curves was measured by planimetry and the flow through the model system calculated from the formula already described.

TABLE I

Comparison of Measured Flow and Calculated Flow in 25 Consecutive Experiments

\begin{tabular}{|c|c|c|c|}
\hline Experiment number & $\begin{array}{l}\text { Measured flow } \\
(1 . / \mathrm{min} .)\end{array}$ & $\begin{array}{c}\text { Calculated flow* } \\
\text { (1./min.) }\end{array}$ & Percentage error \\
\hline $\begin{array}{r}1 \\
2 \\
3 \\
4 \\
5 \\
6 \\
7 \\
8 \\
9 \\
10 \\
11 \\
12 \\
13 \\
14 \\
15 \\
16 \\
17 \\
18 \\
19 \\
20 \\
21 \\
22 \\
23 \\
24 \\
25\end{array}$ & $\begin{array}{l}1 \cdot 69 \\
2 \cdot 80 \\
3 \cdot 95 \\
6 \cdot 39 \\
6 \cdot 12 \\
5 \cdot 71 \\
3 \cdot 33 \\
4 \cdot 26 \\
4 \cdot 47 \\
4 \cdot 91 \\
5 \cdot 22 \\
2 \cdot 57 \\
6 \cdot 35 \\
3 \cdot 53 \\
5 \cdot 73 \\
3 \cdot 66 \\
3 \cdot 23 \\
3 \cdot 04 \\
4 \cdot 02 \\
3 \cdot 08 \\
2 \cdot 12 \\
2 \cdot 11 \\
2 \cdot 95 \\
2 \cdot 24 \\
2 \cdot 99\end{array}$ & $\begin{array}{l}1 \cdot 61 \\
2 \cdot 76 \\
4 \cdot 31 \\
6 \cdot 02 \\
6 \cdot 40 \\
5 \cdot 52 \\
3 \cdot 25 \\
4 \cdot 42 \\
4 \cdot 24 \\
5 \cdot 17 \\
4 \cdot 99 \\
2 \cdot 60 \\
5 \cdot 57 \\
3 \cdot 46 \\
5 \cdot 78 \\
3 \cdot 70 \\
3 \cdot 05 \\
2.94 \\
3 \cdot 48 \\
2.90 \\
2 \cdot 08 \\
1.91 \\
2 \cdot 82 \\
2 \cdot 14 \\
2 \cdot 82\end{array}$ & $\begin{array}{r}-4.7 \\
-1.4 \\
+9.3 \\
-5.8 \\
+4.6 \\
-3.2 \\
-2.4 \\
+3.7 \\
-5.2 \\
+5.3 \\
-4.4 \\
+1 \cdot 2 \\
-12.3 \\
-2.0 \\
+0.9 \\
+1.1 \\
-5.6 \\
-3.3 \\
-13.4 \\
-5.9 \\
-1.9 \\
-9.5 \\
-4.4 \\
-4.5 \\
-5.7\end{array}$ \\
\hline
\end{tabular}

* Using Sparling et al.'s (1960) method of calibration. 


\section{RESULTS}

In 25 consecutive experiments the measured flow through the model system was compared with the calculated flow using Sparling et al.'s (1960) dynamic method of calibration. In these experiments the measured flow was varied from 1.691 ./min. to $6.391 . / \mathrm{min}$. The results are shown in Table I, and Fig. 2. The percentage error ranged from $-13 \cdot 4$ to $+9 \cdot 3$, with a mean error of $-2 \cdot 78$, (standard deviation $5.2 \%$ ). There was a 95 per cent probability that the calculated flow was within -13.0 to $+7 \cdot 4$ per cent of the measured flow.

FIG. 2.-Twenty-five consecutive comparisons of the calculated flow in $\mathrm{ml}$./min. using Sparling et al.'s (1960) method of calibration and the measured flow in $\mathrm{ml} . / \mathrm{min}$. For statistical analysis see text.

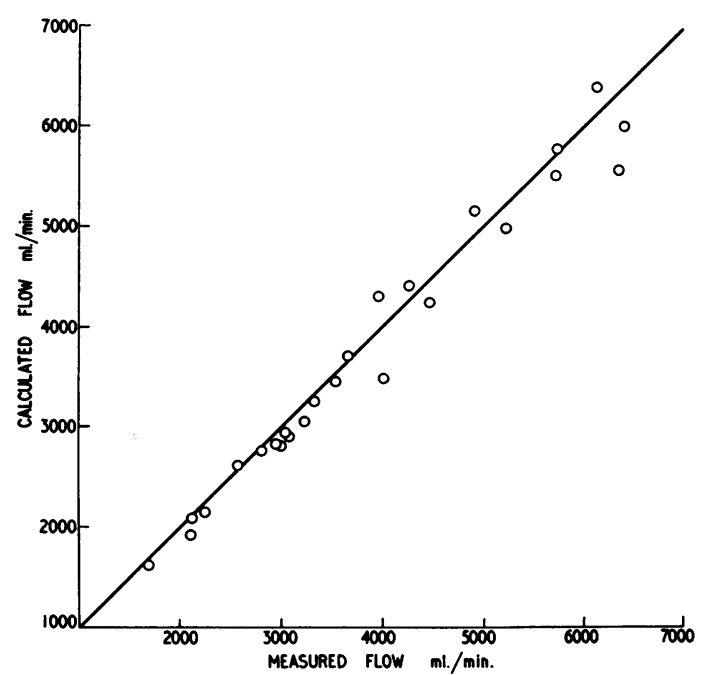

Discussion

Results from a model system show that Sparling et al.'s (1960) dynamic method of calibration offers a 95 per cent probability that the calculated flow will fall within -13.0 to +7.4 per cent of the measured flow. There was, however, a tendency to underestimate the flow but this error was small and independent of flow rate.

The main advantage of this method of calibration over those previously described is that no sample of blood is required for calibration, thus eliminating all chemical and spectrophotometric analysis. In addition, perfect linearity of the measuring and recording system is unimportant if the quantities of dye injected are adjusted so that the peak deflection of the dye curve from the patient and the calibration curve are approximately the same. In common with the method desscribed by Emanuel et al. (1957) a dye that disappears rapidly from the circulation, can be used as it only has to remain within the vascular bed during the initial circulation from the injection site to the sampling site.

The accuracy of this method depends on a constant known sampling rate, exact measurement of the amount of dye injected, and the stability of the measuring and recording system for the time required to obtain the two dye curves. Adequate stability is not difficult to achieve as the interval between the two injections can be reduced to a few seconds if the calibration curve is recorded first, so that the second injection is not delayed on account of recirculation.

These experiments show that Sparling's dynamic method of calibration is sufficiently accurate in a model system to justify its physiological application.

\section{SUMMARY}

In 25 consecutive experiments with a model system, the calculated flow using Sparling et al.'s 
(1960) dynamic method of calibration had a 95 per cent probability of being within $-13 \cdot 0$ to $+7 \cdot 4$ per cent of the actual flow.

We are indebted to Professor P. Armitage for his statistical analysis and to Mr. Clive Hunter, Senior Technician at the Institute of Cardiology for his help with this work. The double roller pump was kindly loaned by New Electronic Products Limited.

\section{APPENDIX \\ Experimental Details}

A Double Roller Pump (A) whose rotation speed had been slightly increased was used throughout this work.

The Model System was similar to that described by Newman et al. (1951) and consisted of three small aspirators $(G)$ of different volumes arranged in series, to represent the right heart, lungs, and left heart respectively. Complete mixing in each aspirator was obtained by a small magnetically rotated stirrer.

Injection and Sampling Site. The injection site (F) was between the roller pump and the first (right heart) aspirator and consisted of an 18 gauge needle fixed rigidly into the system, with its lumen facing downstream. The sampling site (D) was a similar needle about $60 \mathrm{~cm}$. beyond the last (left heart) aspirator with its lumen facing upstream.

Flow Measurement. The water leaving the model system was collected and measured to the nearest $5 \mathrm{ml}$. The volume of water withdrawn through the cuvette was added to this and the minute volume of the pump calculated.

Model System Injection. A 5-ml. all-glass syringe (H) mounted in a holder with a fixed back stop was connected to one limb of a small Y piece, the other limb was attached to a syringe filled with $10 \mathrm{ml}$. water. The Y piece had a minimal dead space and was designed to ensure that all dye was easily and completely washed into the system. The dye was injected rapidly, and flushed into the system by $10 \mathrm{ml}$. of water from the second syringe.

The accuracy of this method was confirmed by weighing the volume delivered through the dry $\mathrm{Y}$ piece. Twelve measurements showed a maximum difference of $0.005 \mathrm{ml}$. when the volume was $2.0 \mathrm{ml} .(0.25 \%)$. After repeated use these syringes delivered slightly larger volumes, the increase was approximately $0.010 \mathrm{ml}$. in $2.0 \mathrm{ml} .(0.5 \%)$. The injection syringes were therefore recalibrated after every six injections.

The Cuvette Withdrawal Pump (B) was a modification (J. Norman, 1962, personal communication) of that originally described by Emanuel et al. (1957). 50-ml. all-glass syringes were used for sampling. The pump withdrawal rate was checked by continuous sampling from a burette and was found to vary maximally by $0.1 \mathrm{ml} . / \mathrm{min}$. in $20 \mathrm{ml} . / \mathrm{min}$. a variation of 0.5 per cent. This variation did not increase if the system from which the sample was drawn was at a pressure of $100 \mathrm{~mm}$. $\mathrm{Hg}$.

The Calibration Loop (E) was a polyvinyl chloride tube $16.0 \mathrm{~cm}$. long, $6.0 \mathrm{~mm}$. internal diameter, filled with siliconed glass beads with an average diameter of $3.0 \mathrm{~mm}$. leaving a fluid volume of $2.6 \mathrm{ml}$. Injections of dye for calibration were made through a short piece of thick-walled rubber tubing fixed between the loop (E) and the sampling site (D).

Calibration Injection. A standard $50 \mu \mathrm{l} .(0.050 \mathrm{ml}$.) syringe $(\mathrm{K})$ was used. The calibration injection consisted of $10 \mu \mathrm{l}$. dye solution in the lower part, and $40 \mu \mathrm{l}$. water in the upper part of the syringe. The accuracy of these syringes when new was extremely good; after 100 injections, however, the volume delivered had fallen by $2 \mu$ l., i.e. 4 per cent of the total volume. The micro-syringes were therefore replaced after every 15 injections.

The Dye. This was Evans Blue (T. 1824). As the spectral absorption of this dye was found to be unstable in the presence of minute traces of metallic salts, all water pumped through the model system was previously passed through an ion exchange plant.

Areas of Dilution Curves. These were measured by polar planimetry. Each area was measured three times; the maximum difference between the readings for any one curve was 2 per cent.

\section{REFERENCES}

Emanuel, R. W., Lacy, W. W., and Newman, E. V. (1957). An improved method for the calibration of continuously recorded dye dilution curves. Circulat. Res., 5, 527.

Friedlich, A., Heimbecker, R., and Bing, R. J. (1950). A device for continuous recording of concentration of Evans Blue dye in whole blood and it application to determination of cardiac output. J. appl. Physiol., 3, 12. 
Hamilton, W. F., Moore, J. W., Kinsman, J. M., and Spurling, R. G. (1928). Simultaneous determination of the pulmonary and systemic circulation times in man and of a figure related to the cardiac output. Amer. J. Physiol., 84, 338.

Milnor, W. R., Talbot, S. A., McKeever, W. P., Marye, R. B., and Newman, E. V. (1953). A photoelectric ear densitometer for continuously recording the arterial concentration of T-1824 in the dye-dilution method. Circulat. Res., 1, 117.

Newman, E. V., Merrell, M., Genecin, A., Monge, C., Milnor, W. R., and McKeever, W. P. (1951). The dye dilution method for describing the central circulation. An analysis of factors shaping the time-concentration curves. Circulation, 4, 735.

Nicholson, J. W., and Wood, E. H. (1951). Estimation of cardiac output and Evans Blue space in man, using an oximeter. J. Lab. clin. Med., 38, 588.

Norman, J. (1959). A stable curvette of high sensitivity for indicator dilution curves. Brit. Heart J., $21,107$.

Sparling, C. M., Mook, G. A., Nieveen, J., Van der Slikke, L. B., and Zijlstra, W. G. (1960). Calibration of dye dilution curves for calculating cardiac output and central blood volume. Congrès Européen de Cardiologie. Acta Tertii Europæi De Cardis Scientia Conventus. Pars altera p. 595., Rome, Excerpta Medica, 1960. 